\title{
Nature and entropy content of the ordering transitions in $\mathrm{RCo}_{2}$
}

\author{
Julia Herrero-Albillos, * Fernando Bartolomé, and Luis Miguel García \\ Instituto de Ciencia de Materiales de Aragón, CSIC, Departamento de Física de la Materia Condensada, Universidad de Zaragoza, \\ Pedro Cerbuna 12, 50009 Zaragoza, Spain
}

Fèlix Casanova, Amílcar Labarta, and Xavier Batlle

Departament de Física Fonamental, Universitat de Barcelona, Diagonal 647, 08028 Barcelona, Catalonia, Spain

(Received 28 July 2005; revised manuscript received 24 January 2006; published 11 April 2006)

\begin{abstract}
Differential scanning calorimetry experiments have been performed under magnetic field in $R \mathrm{Co}_{2} \mathrm{Laves}$ phases compounds $(R=\mathrm{Pr}, \mathrm{Nd}, \mathrm{Tb}, \mathrm{Dy}, \mathrm{Ho}$, and $\mathrm{Er})$. The thermodynamical nature of the ferromagnetic transitions in $\mathrm{PrCO}_{2}$ and $\mathrm{NdCo}_{2}$ is clarified, after the controversy present in the literature about the character of their ordering transitions. The magnetocaloric effect in the compounds showing a first-order magnetostructural transition $(R=\mathrm{Dy}, \mathrm{Ho}$, and $\mathrm{Er})$ is characterized. The latent heat, $L$, and the entropy change at the transition, $\Delta S$, have been studied by inducing the transition sweeping the temperature at a constant field and sweeping the field at a constant temperature. Results from calorimetric data show that $L$ is essentially temperature independent, suggesting that the first order transitions in $\mathrm{RCo}_{2}$ are dominated by the structural effects. The magnetocaloric effect has been also characterized from magnetization data and the results are in excellent agreement with those from calorimetric data. However, the corresponding values of $\Delta S$ for isothermal and isofield experiments differ significantly. We interpret the differences in terms of the broadness of the transitions and prove that the various $\Delta S$ values reported in literature for first-order transitions are not always directly comparable.
\end{abstract}

DOI: 10.1103/PhysRevB.73.134410

PACS number(s): 75.30.Sg, 65.40.Gr, 71.20.Lp

\section{INTRODUCTION}

Cobalt Laves phases, $R \mathrm{Co}_{2}$, and the metamagnetic character of its cobalt sublattice have evoked a far reaching interest since the $1960 \mathrm{~s}$ (for recent reviews on $\mathrm{RCo}_{2}$ compounds, see Refs. 1 and 2). In the compounds where $R$ is a nonmagnetic rare earth, the Co moment can be induced by applying very high magnetic fields $\left(>70 \mathrm{~T}\right.$ for $\left.\mathrm{YCo}_{2}\right),{ }^{3}$ giving rise to a metamagnetic transition. However, in the $\mathrm{RCO}_{2}$ compounds formed with a magnetic rare earth, the internal field is able to induce and polarize the cobalt moment. Due to the intersublattice exchange and third Hund's rule, the rare earth and cobalt moments are coupled parallel in compounds formed with light rare earths (i.e., $R \mathrm{Co}_{2}$ with $R=\mathrm{Pr}, \mathrm{Nd}$, and $\mathrm{Sm}$ are ferromagnets) and antiparallel in those formed with heavy rare earths (i.e., $R \mathrm{Co}_{2}$ with $R=\mathrm{Gd}$, Tb, Dy, $\mathrm{Ho}$, and $\mathrm{Er}$ are ferrimagnetic compounds). ${ }^{4,5}$

In $\mathrm{DyCo}_{2}, \mathrm{HoCO}_{2}$, and $\mathrm{ErCo}_{2}$ compounds, the magnetic ordering to the ferrimagnetic state is coupled to a structural change, leading to a first-order transition at the critical temperature. The high values of the magnetic moment for $R$ $=\mathrm{Dy}, \mathrm{Ho}$, and $\mathrm{Er}$ in $R \mathrm{Co}_{2}$ compounds $^{4-6}$ give rise to a remarkable entropy change $(\Delta S)$ at their first-order transitions, turning this family of compounds into potential candidates for magnetic cooling in the $30-150 \mathrm{~K}$ temperature range. Indeed, the novel trends in high efficiency magnetic refrigeration are based on first-order magnetostructural phase transitions, ${ }^{7-10}$ since magnetization changes abruptly in a narrow temperature range (for reviews on magnetocaloric materials, including $R \mathrm{Co}_{2}$, see Refs. 11-14).

When characterizing the magnetocaloric effect (MCE) from magnetization measurements, $M(H)$ curves are typically used and, therefore, the explored transitions are induced only by sweeping the magnetic field. On the other hand, when the MCE is studied by means of calorimetric data, the transitions are generally induced by temperature. Consequently, when comparing the MCE from the two sets of data, care should be taken because different physical quantities are being swept and measured. As first-order magnetic transitions can be induced both by temperature and magnetic field, it is desirable to compare the dependence of the MCE with both parameters and, moreover, to study them under the same conditions, i.e., in the same instrument and measuring the same physical quantities.

We have studied the first-order transition in $\mathrm{RCo}_{2}$ compounds inducing the transition by sweeping the temperature and the magnetic field by means of magnetization and differential scanning calorimetry (DSC) experiments, and we have found significant differences in $\Delta S$ between isothermal and isofield processes. In fact, these discrepancies were already present in the literature for $\mathrm{ErCo}_{2}$. Giguere et al. ${ }^{15}$ reported differences in $\Delta S$ values obtained from calorimetric data and those obtained from magnetization measurements and they ascribe the discrepancies to the failure of the approximations used (e.g., they found a $12 \%$ difference in the maximum $\Delta S$ value at $7 \mathrm{~T}$ ). Although we have also observed this kind of discrepancies in our data, the agreement between our $\Delta S$ values and Giguere's values is poor, probably due to the different quality of the samples. Conversely, our isofield data are in very good agreement with calorimetric data from Wada et al. ${ }^{16,17}$ and theoretical calculations from de Oliveira et al. ${ }^{18}$ while our isothermal data are in a remarkable agreement with magnetic data from Duc et al. ${ }^{19,20}$ In this paper we investigate the origin of the discrepancy in isofield and isothermal data, emphasizing why different $\Delta S$ values reported in literature are not always directly comparable.

In addition, we also discuss the nature of the ordering transitions in the $R \mathrm{Co}_{2}$ series. Most of the experimental work 
done on the compounds during the last decades assume that only $\mathrm{DyCo}_{2}, \mathrm{HoCo}_{2}$, and $\mathrm{ErCo}_{2}$ display a first-order magnetostructural transition, while all the other compounds display

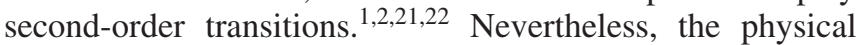
properties measured at that time are not fully conclusive in the determination of the nature of the transition in some of the $R \mathrm{Co}_{2}$ ( $R=$ light rare earth) compounds. Indeed, recent perturbed angular correlation experiments by Forker et al. ${ }^{23}$ have opened a controversy by claiming a first-order character of the transition in $\mathrm{PrCo}_{2}$ and $\mathrm{NdCo}_{2}$ compounds.

There is also a large amount of theoretical work aimed at explaining the nature of the transitions in the whole $R \mathrm{Co}_{2}$ series and why the magnetic transition changes from second to first-order along the series. In particular, the widely accepted Inoue-Shimizu theory, ${ }^{24-26}$ based on a series expansion of the magnetic free energy, predicts the occurrence of a first-order transition in those $R \mathrm{Co}_{2}$ compounds with $T_{c}$ below $\sim 200 \mathrm{~K}$. This would predict a first-order character not only for $\mathrm{DyCo}_{2}, \mathrm{HoCo}_{2}$, and $\mathrm{ErCo}_{2}$ (in general agreement with experimental results), but also for $\mathrm{PrCo}_{2}$ and $\mathrm{NdCo}_{2}$. On the contrary, a more recent work from Khmelevskyi and Mohn, ${ }^{27}$ which takes into account the evolution of the $\mathrm{RCO}_{2}$ lattice constant within the lanthanide series, supports the generally assumed second-order character of the transitions in $\mathrm{PrCo}_{2}$ and $\mathrm{NdCo}_{2}$.

In this scenario, an experiment which definitely solves the riddle of the nature of $\mathrm{PrCo}_{2}$ and $\mathrm{NdCo}_{2}$ transitions is required. Latent heat is a quantity present only in first-order transitions and, therefore, its presence or absence is a direct proof of the nature of the transition. In a DSC, heat flow is directly measured. Consequently, proper integration of the calorimetric signal yields the latent heat in first-order transitions, ${ }^{28}$ while in second-order transitions the signal reflects the continuous change of entropy through the transition. Moreover, the study of the transition using DSC under applied magnetic field also discriminates second- from firstorder transitions. This technique is thus one of the most suitable to determine the thermodynamic character of a phase transition. ${ }^{29,30}$

To summarize, we have performed DSC experiments under applied magnetic field in six compounds of the $R \mathrm{Co}_{2}$ series in order to determine the nature of their ordering transitions and characterize the MCE in these compounds presenting a first-order magnetostructural transition.

The paper is organized as follows: we describe the synthesis and characterization of the samples in Sec. II and the experimental results in Sec. III. We first discuss the nature of the transitions in $\mathrm{PrCo}_{2}$ and $\mathrm{NdCo}_{2}$ (Sec. III A), we go on with the study of the shape of the DSC curves in the firstorder transitions (Sec. III B) and its relation with the anisotropy of the coexistence curves (Sec. III C). In Sec. III D, we present $\Delta S$, enthalpy change and latent heat values obtained from calorimetric and magnetization data and we discuss the effect of the broadness of the transition when comparing field- and temperature-induced transitions. Finally, in Sec. IV, we summarize the main results obtained.

\section{EXPERIMENTAL DETAILS}

All the samples are polycrystalline ingots and were prepared by melting the pure elements in an induction furnace

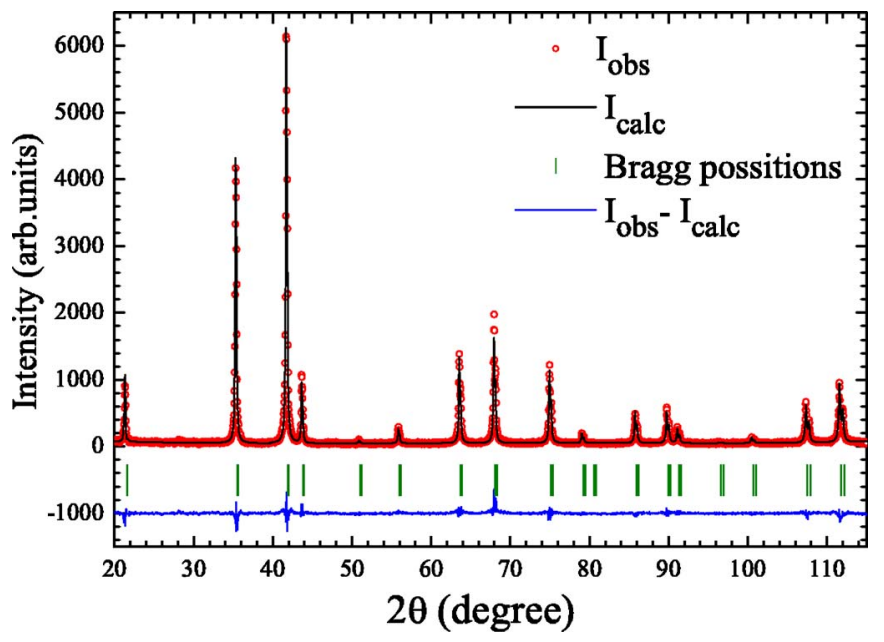

FIG. 1. (Color online) X-ray diffraction data for the $\mathrm{ErCo}_{2}$ sample. Open circles correspond to experimental data, the solid line is the best fit of the spectra to a single phase, vertical lines show the Bragg positions, and the solid line at the bottom is the difference between experimental and fitted data.

under $\mathrm{Ar}$ atmosphere. The resulting ingots were further annealed under $\mathrm{Ar}$ atmosphere at $850{ }^{\circ} \mathrm{C}$ for a week, wrapped in tantalum foil.

$\mathrm{X}$-ray diffraction analysis was performed on powdered samples to check their quality. Rietveld analysis of the diffractograms assured single phase samples with good crystallization. No impurities were found within the $1 \%$ accuracy of powder diffraction methods. X-ray diffractogram for $\mathrm{ErCo}_{2}$ is shown in Fig. 1.

$\mathrm{TbCo}_{2}, \mathrm{HoCo}_{2}$, and $\mathrm{ErCo}_{2}$ samples were analyzed by scanning electron microscopy. In order to check their homogeneity, energy dispersive spectroscopy was carried out in different areas of the samples. The corresponding main phases were found to have the stoichiometric 1:2 composition with small amounts of oxides due to surface oxidation. Very small areas of the samples were found to have a larger amount of $R_{2} \mathrm{O}_{3}$. These rare earth oxides are antiferromagnetic at very low temperatures $(<5 \mathrm{~K})($ Ref. 31$)$ and, therefore, do not contribute to the magnetic behavior of our samples at the temperature range of interest.

The calorimetric measurements were performed in a highsensitivity DSC specially designed to operate over a temperature range from 10 to $300 \mathrm{~K}$ and under magnetic fields up to $5 \mathrm{~T}$. A detailed description of the experimental set up can be found in Ref. 28. Magnetization measurements, $M(T, H)$, from 10 to $300 \mathrm{~K}$ and up to $5 \mathrm{~T}$ were performed in a SQUID Quantum Design magnetometer. In addition, magnetization measurements in $\mathrm{ErCo}_{2}$ were completed up to $9 \mathrm{~T}$ in a commercial Quantum Design extraction magnetometer. The magnetic ordering at zero field occur at $40 \mathrm{~K}, 98 \mathrm{~K}$, $231 \mathrm{~K}, 138 \mathrm{~K}, 78 \mathrm{~K}$, and $34 \mathrm{~K}$ for $\mathrm{PrCo}_{2}, \mathrm{NdCo}_{2}, \mathrm{TbCo}_{2}$ $\mathrm{DyCo}_{2}, \mathrm{HoCo}_{2}$, and $\mathrm{ErCo}_{2}$, respectively. These data are fully consistent with those previously reported. . $^{1,415-18,20,21,32-46}$

The $M(T, H)$ surface for the compounds presenting a firstorder transition $\left(\mathrm{DyCo}_{2}, \mathrm{HoCo}_{2}\right.$, and $\left.\mathrm{ErCo}_{2}\right)$ are shown in Fig. 2. It is worth stressing that, in $\mathrm{HoCo}_{2}$ and $\mathrm{ErCo}_{2}$, transitions are very sharp but $\mathrm{DyCo}_{2}$ does not show such a char- 

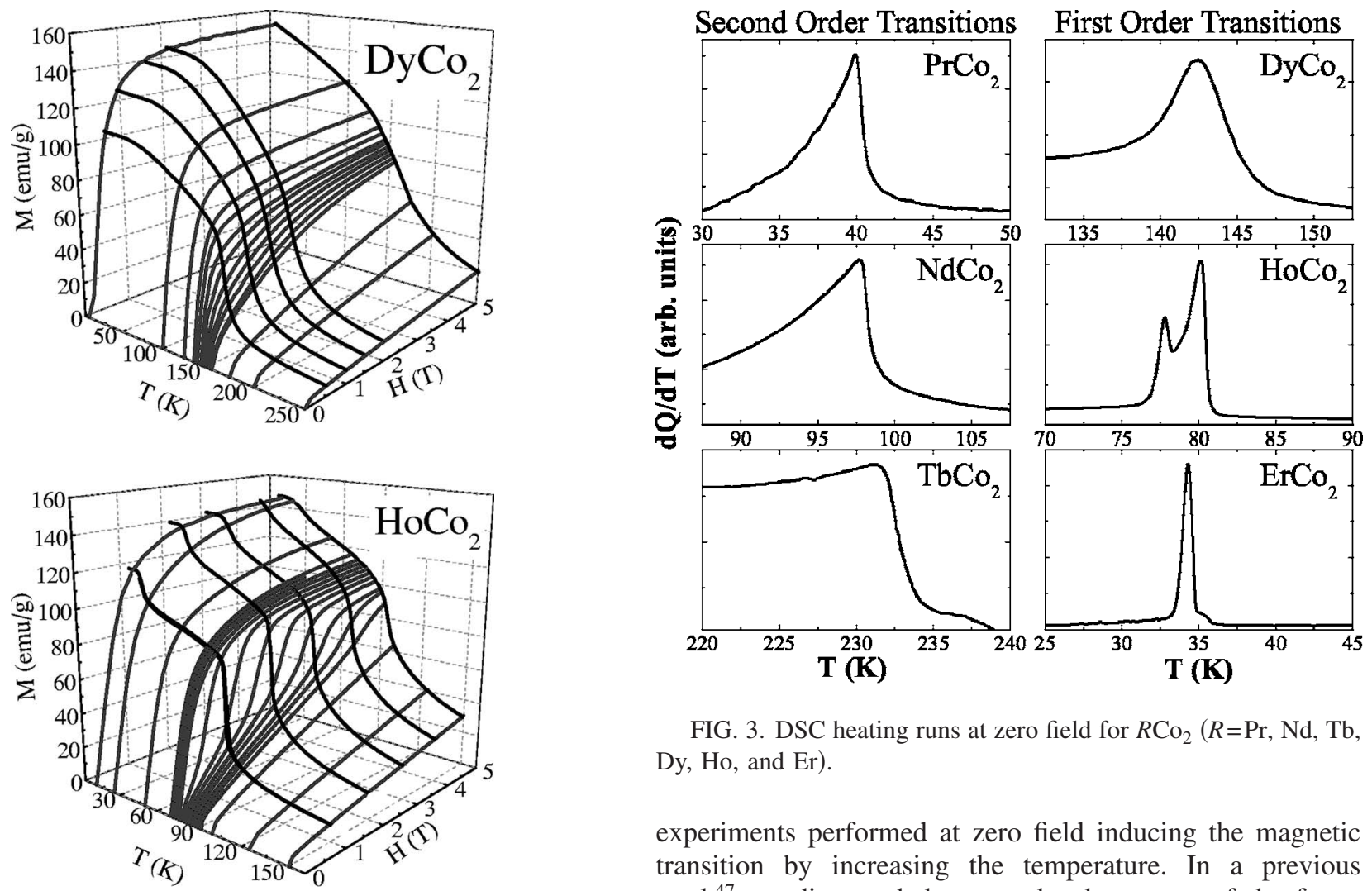

FIG. 3. DSC heating runs at zero field for $R \mathrm{Co}_{2}(R=\mathrm{Pr}, \mathrm{Nd}, \mathrm{Tb}$, Dy, Ho, and Er).

experiments performed at zero field inducing the magnetic transition by increasing the temperature. In a previous work ${ }^{47}$ we discussed the second-order nature of the ferromagnetic transition for $\mathrm{NdCo}_{2}$ and $\mathrm{PrCo}_{2}$ from zero field data. In order to clearly establish the nature of these phase transitions, we have performed DSC experiments under applied field in $\mathrm{PrCO}_{2}$ and $\mathrm{NdCo}_{2}$. As can be seen in Fig. 4, the $\lambda$-shape transition is only manifested at zero field for both compounds. When a magnetic field is applied, the peak

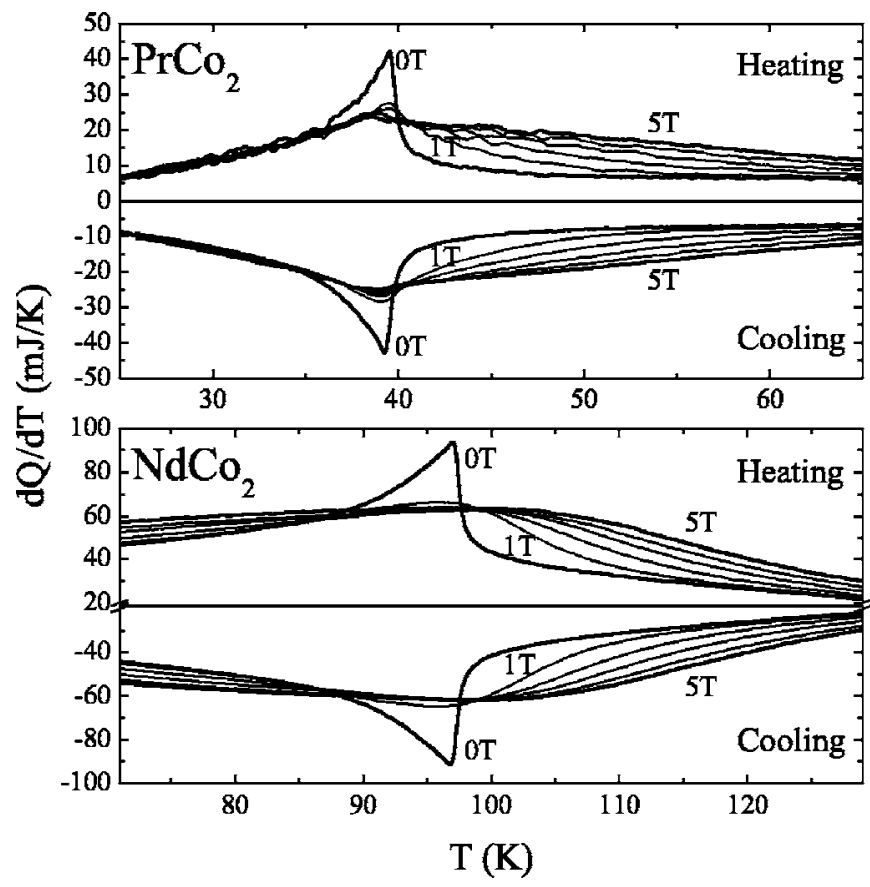

FIG. 4. DSC curves as a function of temperature under selected applied fields $(H=0,1,2,3,4$, and $5 \mathrm{~T})$ for $\mathrm{PrCo}_{2}$ and $\mathrm{NdCo}_{2}$. 
broadens but the maximum does not shift towards higher temperatures as the field is increased. Furthermore no hysteresis effects have been observed between cooling and heating runs for any of the applied fields.

In view of this, the measurements under applied fields up to $5 \mathrm{~T}$ fully rule out the proposed first-order nature of $\mathrm{PrCo}_{2}$ and $\mathrm{NdCO}_{2}$ magnetic transitions in Ref. 23. Forker and coworkers based their conclusion on two features of the perturbed angular correlation (PAC) spectra of ${ }^{111} \mathrm{Cd}$, which should allow us to discriminate the nature of the phase transitions; the variation of the magnetic interaction frequency and the broadening of the PAC lines near $T_{c} \cdot{ }^{23}$ The authors discuss in detail the coexistence of magnetically ordered and disordered phases near $T_{c}$ in all their samples, leading to a distribution of the ordering temperatures of about $1-2 \mathrm{~K}$ (a fact that we have also observed in some of our samples, as we discuss below). The lack of a fine temperature scanning near $T_{c}$ together with the cited phase-coexistence makes it very difficult to use PAC spectra as a tool to discriminate between first- and second-order phase transitions. In contrast, DSC is the technique of choice when aiming at determine the nature of a transition, especially in those cases hard to discriminate. In our opinion, data shown in the present work unambiguously determine the second-order character of the $\mathrm{NdCo}_{2}$ and $\mathrm{PrCo}_{2}$ ordering transitions.

\section{B. Differential scanning calorimetry in first-order transitions for $\mathrm{DyCo}_{2}, \mathrm{HoCo}_{2}$, and $\mathrm{ErCo}_{2}$}

$\mathrm{DyCo}_{2}, \mathrm{HoCo}_{2}$, and $\mathrm{ErCo}_{2}$ show first-order magnetostructural transitions and therefore present relevant MCE. In order to fully characterize them, we have performed DSC measurements both sweeping the temperature at a constant field [which will be noted as $\operatorname{DSC}_{H}(T)$ from now on] and sweeping the applied field at a constant temperature $\left[\operatorname{DSC}_{T}(H)\right]$.

$\mathrm{DSC}_{H}(T)$ experiments were carried out at a rate of $3 \mathrm{~K} / \mathrm{min}$ for heating runs and at $1 \mathrm{~K} / \mathrm{min}$ for cooling runs. $\mathrm{DSC}_{T}(H)$ experiments were carried out by increasing and decreasing the field at both $1 \mathrm{~T} / \mathrm{min}$ and $0.1 \mathrm{~T} / \mathrm{min}$. In this way, the transition was induced by the temperature as well as by the magnetic field, at different rates and going from the paramagnetic to the ferrimagnetic region and vice versa. The resulting $\mathrm{DSC}_{H}(T)$ and $\mathrm{DSC}_{T}(H)$ signals are shown in Figs. 5 and 6 , respectively.

For the three compounds, $\operatorname{DSC}_{H}(T)\left[\operatorname{DSC}_{T}(H)\right]$ curves exhibit the typical field (temperature) dependence of the critical temperature (critical field) for a first-order transition. As it is also expected for a first-order transition, $\mathrm{ErCo}_{2}$ and $\mathrm{HoCo}_{2}$ curves show thermal and field hysteresis as well as sharp peaks.

The first-order character of $\mathrm{DyCo}_{2}$ transition is well established from the above cited dependence of the critical temperature with the applied field, resistivity data ${ }^{48}$ and theoretical calculations. ${ }^{24-27}$ However, $\operatorname{DSC}_{H=0 T}(T)$ curves for $\mathrm{DyCo}_{2}$ show a very wide peak which becomes even broader as soon as a magnetic field is applied $(\sim 0.3 \mathrm{~T})$. A similar behavior can be observed in the $\operatorname{DSC}_{T}(H)$ curves for $\mathrm{DyCo}_{2}$ (see Fig. 6). Moreover, we have not observed any thermal or field hysteresis (in contrast with previous DSC results at zero

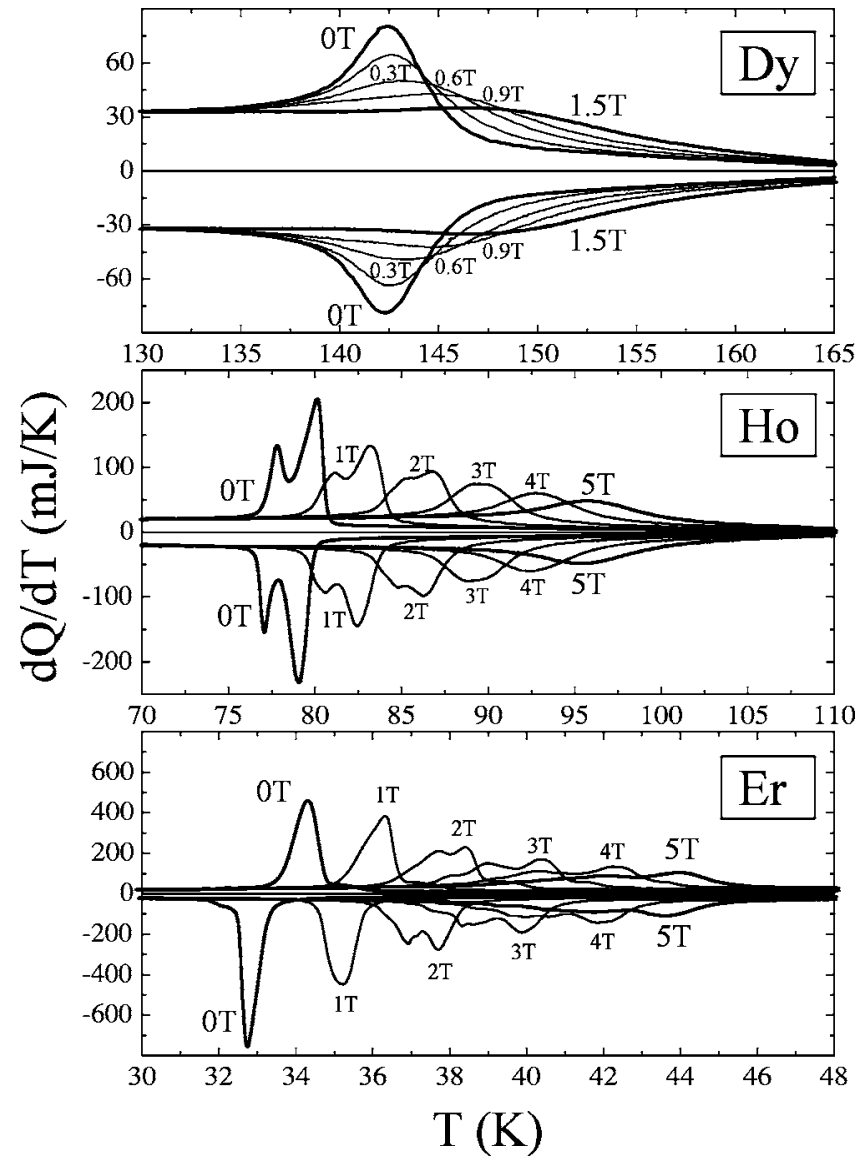

FIG. 5. DSC curves as a function of temperature under selected applied fields for $\mathrm{DyCo}_{2}, \mathrm{HoCo}_{2}$, and $\mathrm{ErCO}_{2}$. Positive (negative) signals correspond to the heating (cooling) runs.

field). ${ }^{49}$ This weak first-order behavior could be also seen in the $\mathrm{DyCo}_{2}$ magnetization surface (see Fig. 2). Previous experimental results ${ }^{1,20,33}$ have suggested that this weak firstorder character may originate from the small size of the discontinuity of the free energy derivatives at the transition.

Except for hysteresis effects, no differences in $\Delta S$ values at the transition nor in the shape of the curves were observed between cooling and heating measurements for $\mathrm{DyCo}_{2}$ and $\mathrm{HoCo}_{2}$ (Fig. 5). For $\mathrm{ErCo}_{2}$ compound, due to the sharpness of the DSC peaks for the lowest applied fields, the sweeping rate affects the measurement, causing up to $15 \%$ difference in the magnitude of MCE. Similarly, no difference between measurements carried out by increasing and decreasing the field was detected in $\operatorname{DSC}_{T}(H)$ data (Fig. 6), only a finer peak structure was perceived for runs performed at $0.1 \mathrm{~T} / \mathrm{min}$. Therefore, in what follows, we shall only refer to the results obtained by heating or by increasing the field.

\section{Fine peak structure in the calorimetric curves}

All $\mathrm{ErCo}_{2}$ and $\mathrm{HoCo}_{2}$ isothermal and isofield calorimetric curves show a peak structure. For the sake of clarity, some of the heating curves for the two compounds are shown again in Fig. 7.

In the $\mathrm{ErCo}_{2}$ calorimetric curve at zero field, a main peak is observed. Under an applied magnetic field, this peak splits 


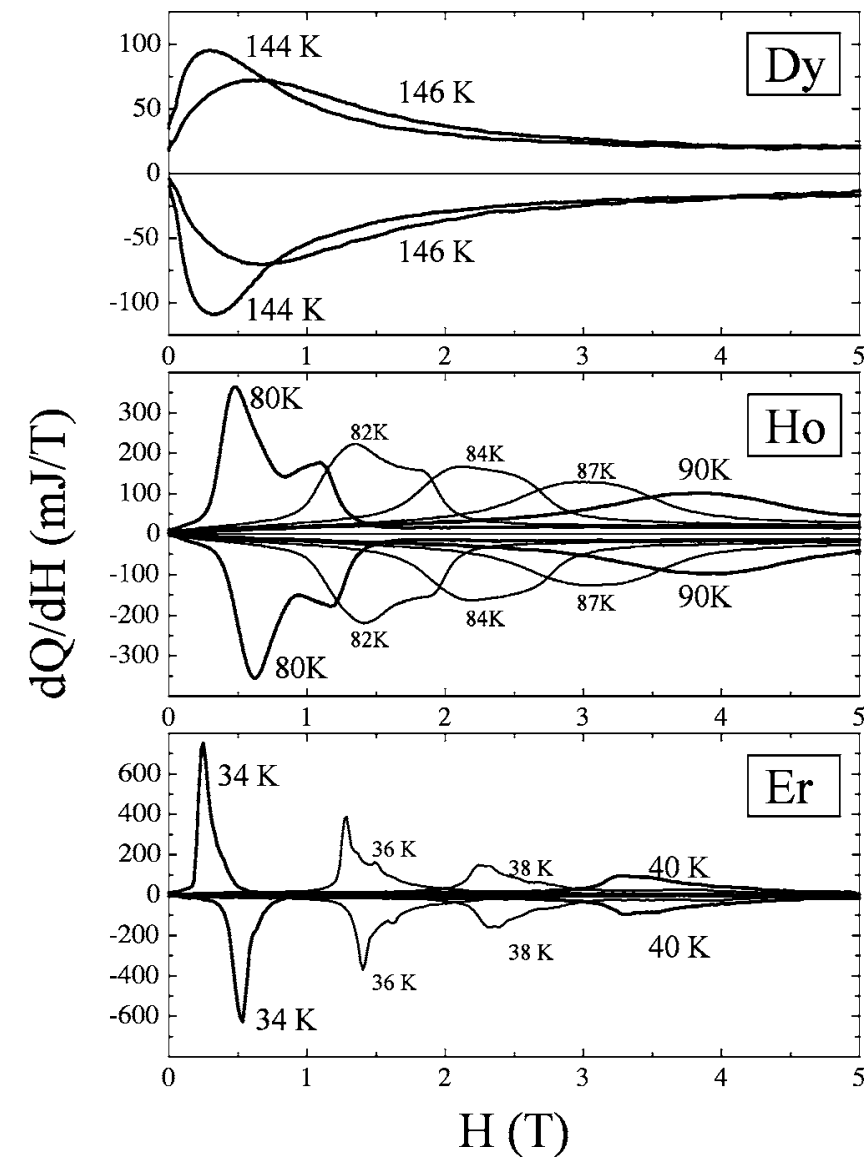

FIG. 6. DSC curves as a function of applied field at selected temperatures for $\mathrm{DyCo}_{2}, \mathrm{HoCo}_{2}$, and $\mathrm{ErCo}_{2}$. Positive (negative) signals correspond to measurements carried decreasing (increasing) the applied magnetic field.

into three distinct peaks which gradually move away from each other as the field is increased. A smaller peak in the calorimetric curves can also be observed $1 \mathrm{~K}$ above the highest peak, which will be discussed later. At $3 \mathrm{~T}$ the four peaks can be fully distinguished, as shown in Fig. 7. Each calorimetric curve has been fitted to the sum of four pseudo-Voigt functions in order to precisely determine the peak positions as a function of the applied field. Results are shown in the inset of Fig. 7.

Magnetization and magnetoresistance measurements on $\mathrm{ErCO}_{2}$ single crystal by Aleksandryan et al. ${ }^{50}$ revealed that, for a fixed magnetic field, $T_{c}$ depends on the relative orientation of the field with respect to the three crystallographic directions [100], [110], and [111]. Hence, each microcrystal in a polycrystalline sample also has a different ordering temperature depending on its relative orientation with respect to the external magnetic field. Each one contributes to the DSC curve with a peak centered at its own ordering temperature. If the microcrystals are randomly orientated within the sample, DSC curves should present a single wide feature arising from the sum of the contributions of all of them. This is not the case for our calorimetric curves in $\mathrm{ErCO}_{2}$, as it is shown in Fig. 7, yielding the conclusion that in the process of sample synthesis the crystals have grown preferentially in three crystallographic directions and their equivalent cubic

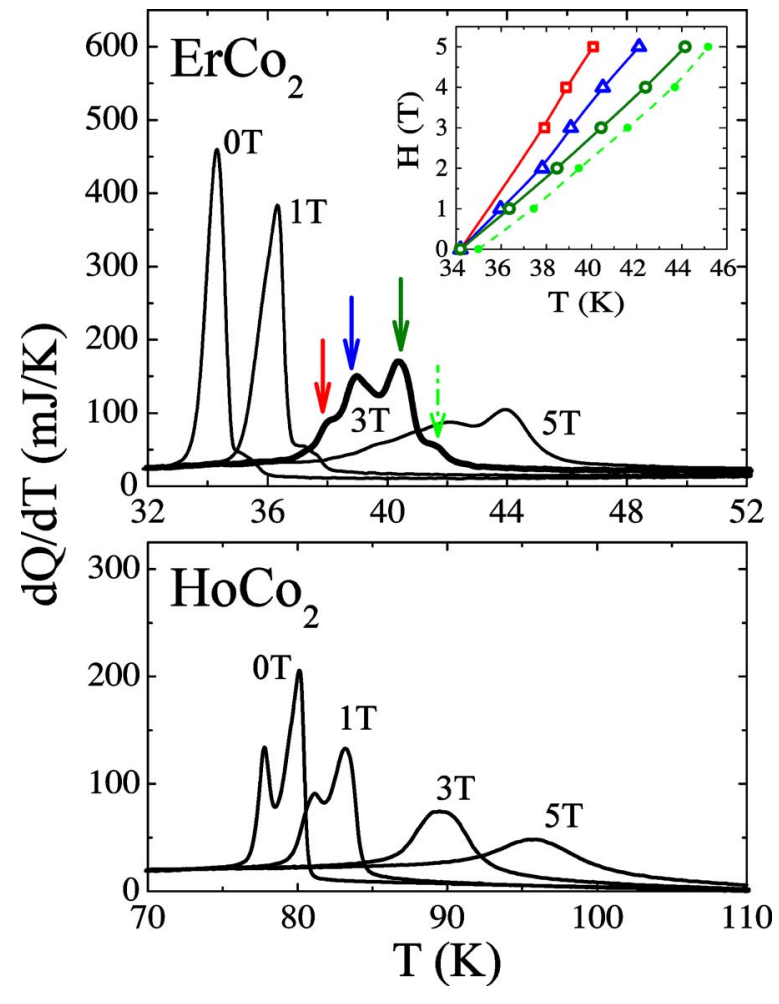

FIG. 7. (Color online) $\mathrm{DSC}_{H}(T)$ heating runs for $\mathrm{ErCo}_{2}$ and $\mathrm{HoCo}_{2}(H=0,1,3$, and $5 \mathrm{~T})$. (Inset) Temperature and field dependence of the calorimetric peaks in the polycrystalline sample $\mathrm{ErCo}_{2}$

ones. Furthermore, this peak structure can be also observed in the derivative of the magnetization curve shown in Fig. 8. The agreement between the critical temperatures deduced from our DSC data in a polycrystalline sample and those reported in Ref. 50 from a single crystal is remarkable.

The case for $\mathrm{HoCo}_{2}$ is quite different. The ordering temperature of this compound does not depend on the relative orientation of the crystallographic directions and the field (i.e., the coexistence curve is isotropic with respect to the crystallographic directions ${ }^{51}$ ) and only one peak should be expected in the DSC curves. However, $\mathrm{HoCo}_{2}$ calorimetric curves show two peaks (Fig. 7), which become broader as

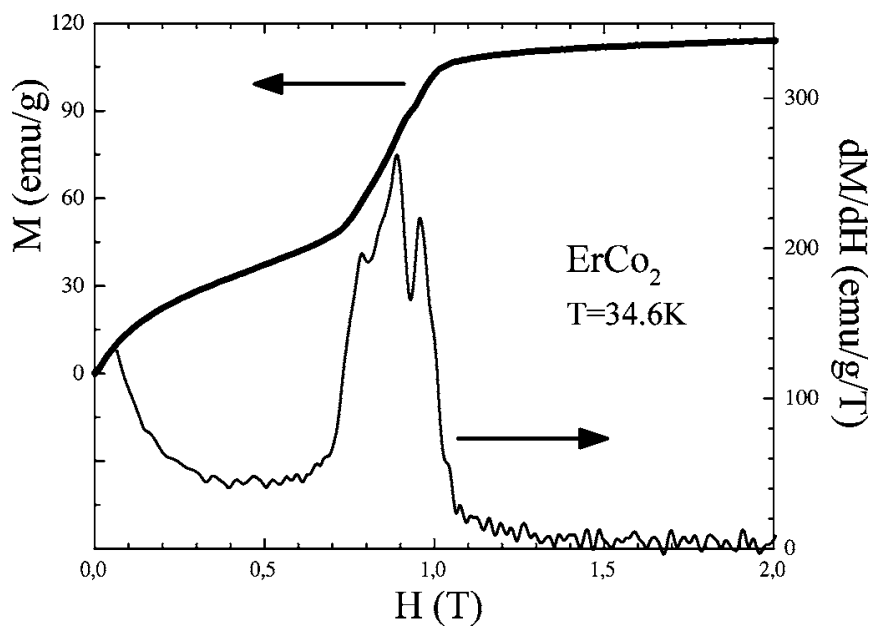

FIG. 8. $M(H)$ and its derivative in $\mathrm{ErCo}_{2}$ at $34.6 \mathrm{~K}$. 
TABLE I. Entropy change $\left(\Delta S_{H}\right)$, latent heat $(L)$, and enthalpy change $\left(\Delta E_{H}\right)$ at the $\mathrm{DyCo}_{2}$ first-order transition obtained from DSC on heating at constant fields.

\begin{tabular}{ccc}
\hline \hline$H(\mathrm{~T})$ & $\Delta S_{H}\left(\mathrm{~J} \mathrm{~kg}^{-1} \mathrm{~K}^{-1}\right)$ & $L=\Delta E_{H}\left(\mathrm{~J} \mathrm{~kg}^{-1} \times 10^{3}\right)$ \\
\hline 0 & 8.5 & 1.2 \\
0.3 & 8.1 & 1.1 \\
0.6 & 6.5 & 0.9 \\
0.9 & 6.3 & 0.9 \\
1.2 & 5.0 & 0.7 \\
1.5 & 4.0 & 0.6 \\
\hline \hline
\end{tabular}

the field is increased or the temperature raised. The temperature (field) difference between the peaks remains constant as the field (temperature) is increased, so that the peaks coalesce in an unresolved feature as their width increases. At $5 \mathrm{~T}(90 \mathrm{~K})$ only one wide peak can be observed.

The origin of these two peaks in $\mathrm{HoCo}_{2}$ as well as the cited minor feature located at a higher temperature in $\mathrm{ErCo}_{2}$ may be due to sample inhomogeneities. As stated in Sec. II, $\mathrm{x}$-ray diffractograms and energy dispersive spectroscopy assure single phase samples but are compatible with small offstoichiometry deviations in the samples.

Gratz et al..$^{52}$ have reported a strong dependence of the critical temperature with the stoichiometry in the metamagnetic compound $\mathrm{ErCo}_{3}$. While the stoichiometric sample has an ordering temperature of $100 \mathrm{~K}$, they report that $\mathrm{ErCo}_{2.88}$ orders at $65 \mathrm{~K}$. We propose that the additional peaks in the calorimetric curves for $\mathrm{HoCo}_{2}$ and $\mathrm{ErCo}_{2}$ samples are a consequence of the presence of a main $\mathrm{RCo}_{2}$ phase, ordering at $T_{c}$, together with a a slightly off-stoichiometric phase, ordering at a somewhat different temperature. In fact, the critical temperatures found in the literature vary mostly between $32 \mathrm{~K}$ and $34 \mathrm{~K}$ for $\mathrm{ErCo}_{2}$ (Refs. 16-18, 20, 21, 32-39, and 41-43) and $75 \mathrm{~K}$ and $78 \mathrm{~K}$ for $\mathrm{HoCo}_{2}$ (Refs.16, 20, 21, 44, and 41-45). However values from $30 \mathrm{~K}$ (Ref. 46) to $36 \mathrm{~K}$ (Refs. 4, 15, and 40) and $74 \mathrm{~K}$ (Refs. 38 and 39) to 80-95 K (Refs. 4, 18, 40, and 46) can be also found for these compounds, respectively. This leads to the conclusion that their critical temperatures are very sensitive to small deviations in the stoichiometry.
D. Entropy change, enthalpy change, and latent heat at $\mathrm{DyCo}_{2}, \mathrm{HoCo}_{2}$, and $\mathrm{ErCo}_{2}$ ferrimagnetic transitions

$\Delta S$ and the latent heat $(L)$ at the transition for the three compounds is determined by numerical integration of $\operatorname{DSC}_{T}(H)$ and $\operatorname{DSC}_{H}(T)$ signals. ${ }^{28,30} \Delta S$ and $L$ values for the temperature-induced transition in $\mathrm{DyCo}_{2}$ are shown in Table I. Values for both temperature- and field-induced transitions are shown in Tables II and III for $\mathrm{HoCO}_{2}$ and $\mathrm{ErCo}_{2}$, respectively. As argued before, only data for heating and increasing the field (at a rate of $0.1 \mathrm{~T} / \mathrm{min}$ ) runs are presented. The values are in general agreement with those previously reported from indirect experimental methods and theoretical models. ${ }^{15-20,53,54}$

In equilibrium, the enthalpy change of a magnetic system at the first-order transition is

$$
\Delta E=\int T d S-\int M d H=L-\int M d H,
$$

where the integral is evaluated along the transition region.

In isofield experiments, the second term vanishes and $\Delta E_{H}=L$. In isothermal ones, $L$ is given by $T_{c} \Delta S_{T}$ but in order to obtain the enthalpy change $\Delta E_{T}$, the second term in Eq. (1) has to be evaluated from the magnetization measurements. The obtained $\Delta E$ values are also shown in Tables I-III.

It is worth noting that, along the $\mathrm{RCo}_{2}$ series, $T \Delta S$ is approximately constant, for fixed $H / T$ values. Consequently, $\Delta S$ decreases as $T_{c}$ increases along the series. The univocal relationship between $T_{c}$ and the critical field $H_{c}$ allows to assign a temperature for $\Delta S$ obtained from isofield measurements and thus in Fig. 9 we show the maximum $\Delta S$ values obtained as a function of $T_{c}$ from both isofield and isothermal DSC measurements. The dashed line is the hyperbolic branch $T \Delta S=1350 \mathrm{~J} / \mathrm{kg}$, fitting our whole set of data. The data available in literature are consistent with the trend shown in Fig. 9, ${ }^{19,20,55}$ although the agreement with a constant $T \Delta S$ curve is not so good.

The strong variation of $\Delta S$ with $T$ had been attributed to the first-order character of the transitions. ${ }^{18-20,55}$ However, it is interesting to note that the $\Delta S$ values given in Refs. 19 and 20 for $\mathrm{TbCo}_{2}$ (which undergoes a second-order magnetic transition with a huge rhombohedral distortion ${ }^{59,60}$ ) falls as

TABLE II. Entropy change, latent heat, and enthalpy change at the $\mathrm{HoCo}_{2}$ first-order transition obtained from DSC on heating at constant fields $\left(\Delta S_{H}\right.$ and $\left.L=\Delta E_{H}\right)$ and increasing the field at a constant temperatures $\left(\Delta S_{T}, L\right.$, and $\left.\Delta E_{T}\right)$.

\begin{tabular}{|c|c|c|c|c|c|c|}
\hline \multicolumn{3}{|c|}{ Constant field } & \multicolumn{4}{|c|}{ Constant temperature } \\
\hline $\begin{array}{c}H \\
(\mathrm{~T})\end{array}$ & $\begin{array}{c}\Delta S_{H} \\
\left(\mathrm{~J} \mathrm{~kg}^{-4} \mathrm{~K}^{-1}\right)\end{array}$ & $\begin{array}{c}L=\Delta E_{H} \\
\left(\mathrm{~J} \mathrm{~kg}^{-1} \times 10^{3}\right)\end{array}$ & $\begin{array}{c}T \\
(\mathrm{~K})\end{array}$ & $\begin{array}{c}\Delta S_{T} \\
\left(\mathrm{~J} \mathrm{~kg}^{-1} \mathrm{~K}^{-1}\right)\end{array}$ & $\begin{array}{c}L=T \cdot \Delta S_{T} \\
\left(\mathrm{~J} \mathrm{~kg}^{-1} \times 10^{3}\right)\end{array}$ & $\begin{array}{c}\Delta E_{T} \\
\left(\mathrm{~J} \mathrm{~kg}^{-1} \times 10^{3}\right)\end{array}$ \\
\hline 0 & 20.0 & 1.6 & 80 & 15.0 & 1.2 & 1.3 \\
\hline 1 & 17.6 & 1.4 & 82 & 12.9 & 1.1 & 1.2 \\
\hline 2 & 14.9 & 1.3 & 84 & 10.6 & 0.9 & 1.0 \\
\hline 3 & 12.3 & 1.1 & 86 & 7.9 & 0.7 & 0.8 \\
\hline 4 & 10.5 & 1.0 & & & & \\
\hline 5 & 8.9 & 0.8 & & & & \\
\hline
\end{tabular}


TABLE III. Entropy change, latent heat, and enthalpy change at the $\mathrm{ErCo}_{2}$ first-order transition obtained from DSC on heating at constant fields $\left(\Delta S_{H}\right.$ and $\left.L=\Delta E_{H}\right)$ and increasing the field at a constant temperatures $\left(\Delta S_{T}, L\right.$, and $\left.\Delta E_{T}\right)$.

\begin{tabular}{|c|c|c|c|c|c|c|}
\hline \multicolumn{3}{|c|}{ Constant field } & \multicolumn{4}{|c|}{ Constant temperature } \\
\hline $\begin{array}{c}H \\
(\mathrm{~T})\end{array}$ & $\begin{array}{c}\Delta S_{H} \\
\left(\mathrm{~J} \mathrm{~kg}^{-1} \mathrm{~K}^{-1}\right)\end{array}$ & $\begin{array}{c}L=\Delta E_{H} \\
\left(\mathrm{~J} \mathrm{~kg}^{-1} \times 10^{3}\right)\end{array}$ & $\begin{array}{c}T \\
(\mathrm{~K})\end{array}$ & $\begin{array}{c}\Delta S_{T} \\
\left(\mathrm{~J} \mathrm{~kg}^{-1} \mathrm{~K}^{-1}\right)\end{array}$ & $\begin{array}{c}L=T \cdot \Delta S_{T} \\
\left(\mathrm{~J} \mathrm{~kg}^{-1} \times 10^{3}\right)\end{array}$ & $\begin{array}{c}\Delta E_{T} \\
\left(\mathrm{~J} \mathrm{~kg}^{-1} \times 10^{3}\right)\end{array}$ \\
\hline 0 & 43.3 & 1.5 & 34 & 36.2 & 1.2 & 1.3 \\
\hline 1 & 41.2 & 1.5 & 36 & 34.3 & 1.2 & 1.2 \\
\hline 2 & 39.3 & 1.5 & 38 & 31.6 & 1.2 & 1.5 \\
\hline 3 & 37.3 & 1.4 & & & & \\
\hline 4 & 33.0 & 1.4 & & & & \\
\hline 5 & 29.1 & 1.3 & & & & \\
\hline
\end{tabular}

well into the same constant- $T \Delta S$ curve (see Fig. 9).

$T \Delta S$ equals $L$ in field-induced transitions and gives a good estimation of the latter in temperature-induced ones. $L$ reflects the energy difference between the high- and lowtemperature phases and our results indicate that this energy difference is rather independent of temperature in $\mathrm{RCo}_{2}$. In principle, the magnetic contribution should show the opposite behavior, as the total magnetic entropy available $[\ln (2 \mathrm{~J}$ $+1)$ ] is very similar for the three compounds but the critical temperatures (and thus, the exchange energies) vary from about 30 to $150 \mathrm{~K}$. Therefore, the $T \Delta S$ product suggests that the free energy change at the transition is highly dominated by the structural effects, both in first- and second-order $\mathrm{RCo}_{2}$ ordering transitions.

In contrast, in a first-order transition ruled by the magnetic contribution, one would expect that the magnitude

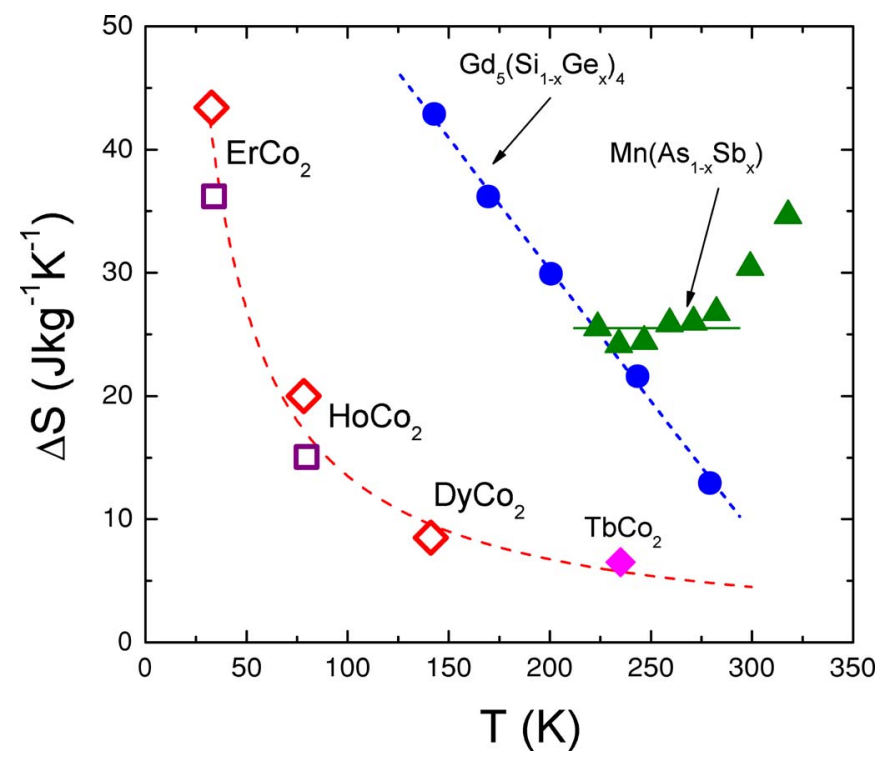

FIG. 9. (Color online) $\Delta S$ values as a function of critical temperature at the magnetostructural transitions of some magnetocaloric compounds. Open diamonds and squares are $\Delta S$ values for $\mathrm{ErCo}_{2}, \mathrm{HoCO}_{2}$, and $\mathrm{DyCo}_{2}$ from isofield and isothermal DSC measurements, respectively. Full circles are $\Delta S$ for $\mathrm{Gd}_{5}\left(\mathrm{Si}_{x} \mathrm{Ge}_{1-x}\right)_{4}$ (Refs. 29, 56, and 57), full triangles for $\mathrm{MnAs}_{1-x} \mathrm{Sb}_{x}$ (Refs. 55 and 58), and full diamond for $\mathrm{TbCo}_{2}$ (Refs. 19 and 20). which remains constant as a function of temperature should be the entropy [dominated by the $\ln (2 J+1)$ term] instead of the latent heat. This is indeed the case for a certain range of compositions $(x=0.1-0.3)$ and temperatures $(222-300 \mathrm{~K})$ in the $\mathrm{MnAs}_{1-x} \mathrm{Sb}_{x}$ first-order transitions, ${ }^{55,58}$ as shown in Fig. 9. This fact is very important for technological reasons, as that family would allow to prepare a useful composite for magnetic cooling below room temperature. ${ }^{58}$ An intermediate case is $\operatorname{Gd}_{5}\left(\mathrm{Si}_{x} \mathrm{Ge}_{1-x}\right)_{4}$, for which selected data $29,56,57$ are also shown in Fig. 9.

The results on $\operatorname{Gd}_{5}\left(\mathrm{Si}_{x} \mathrm{Ge}_{1-x}\right)_{4}$ allowed to some of us to point out the scaling of $\Delta S$ with $T_{c}$ in this family for a wide range of temperatures and compositions, ${ }^{56}$ reflecting a balance between structural and magnetic effects at the firstorder transition.

In order to study the differences in the entropy change obtained from isofield and isothermal DSC experiments, we have also determined $\Delta S$ at the transition from isofield and isothermal magnetization curves applying the ClausiusClapeyron equation

$$
\Delta S=-\Delta M \frac{d H_{c}}{d T_{c}}
$$

or from isothermal magnetization curves applying the Maxwell relations within the transition region ${ }^{61,62}$

$$
\Delta S=\int_{H_{a}}^{H_{b}}\left(\frac{\partial M}{\partial T}\right)_{H} d H
$$

(where the transition takes place between $H_{a}$ and $H_{b}$ ).

When applying the Clausius-Clapeyron equation, the magnetization jump $(\Delta M)$ at the transition has to be evaluated. Since real transitions occur within a range of temperature and field, contributions coming from other phenomena occurring in the same region should be separated. In particular, for the $M(H)$ curves, the magnetization process due to the increase of the applied magnetic field has to be subtracted. For this reason, the $M(H)$ curve is linearly extrapolated in the vicinity of the transition region for the paramagnetic phase as well as for the ferrimagnetic phase (see Fig. 10). The points where the curve diverges from the two straight lines define the transition limits. $\Delta M$ is then evalu- 


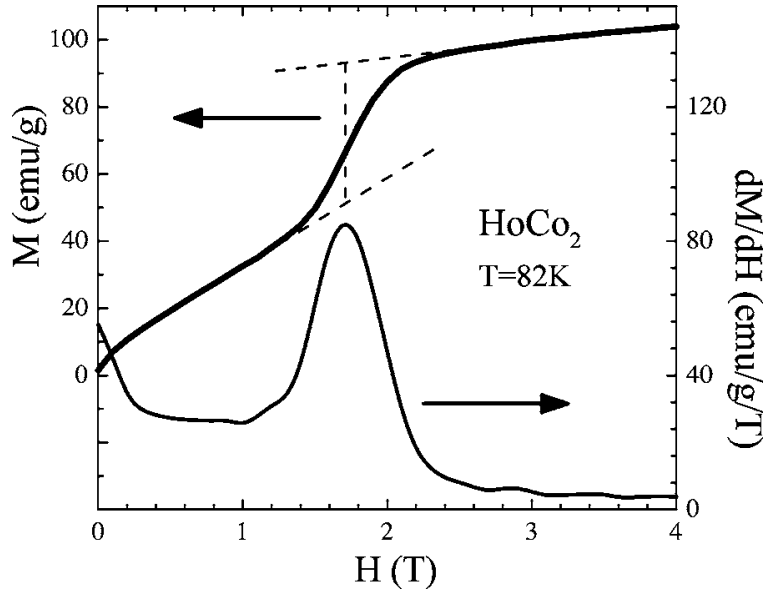

FIG. 10. $M(H)$ and its derivative in $\mathrm{HoCo}_{2}$ at $82 \mathrm{~K}$.

ated as the difference between the lines at the critical field, which is defined for each isothermal $M(H)$ curve as the field corresponding to the inflection point within the transition region (see Fig. 10). For $M(T)$ curves, the same procedure can be applied to determine $\Delta M$ and the transition limits. In this case, the two lines are parallel (see Fig. 11).

Figure 12 shows the values of $\Delta S$ obtained from both calorimetric data and magnetization curves as a function of the temperature for $\mathrm{HoCo}_{2}$. We compare $\Delta S$ obtained from magnetization and calorimetric data and for both temperature and field induced transitions. It is worth stressing the agreement between $\Delta S$ obtained from $\operatorname{DSC}_{H}(T)$ and from $M(T)$ using the Clausius-Clapeyron equation $\left[\mathrm{C}-\mathrm{C}_{M(T)}\right.$ in the figures]. Besides, we also point out the agreement between $\Delta S$ obtained from $\operatorname{DSC}_{T}(H)$ and from $M(H)$ using the ClausiusClapeyron equation $\left[\mathrm{C}-\mathrm{C}_{M(H)}\right]$ and the Maxwell relation [Eq. (3)]. Provided that the transition is induced by the same driving physical parameter, either $\mathrm{T}$ or $\mathrm{H}$, the agreement between the calorimetric and magnetic data, although very satisfactory, was indeed expected.

In contrast, $\Delta S$ values obtained from isofield measurements are 20\% larger than those obtained from isothermal measurements for the lower temperatures and fields and up

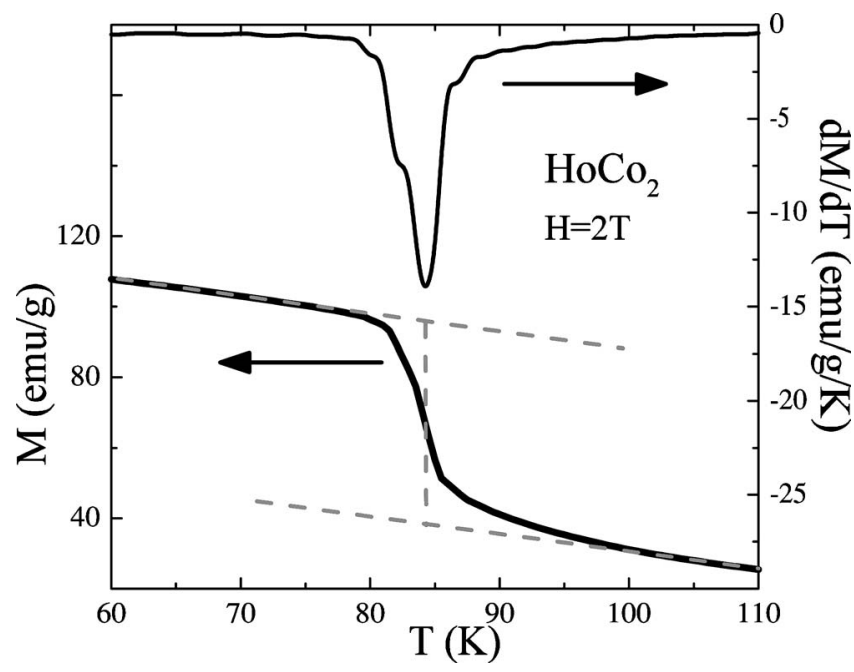

FIG. 11. $M(T)$ and its derivative in $\mathrm{HoCO}_{2}$ at $2 \mathrm{~T}$.

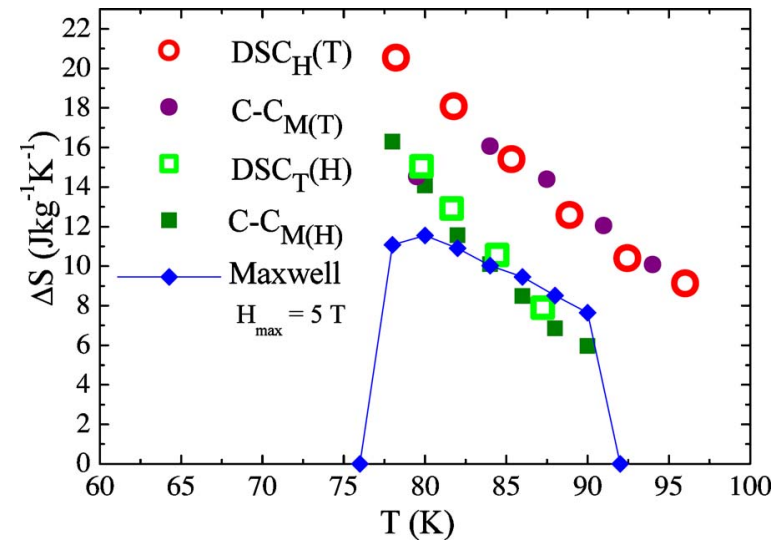

FIG. 12. (Color online) Entropy change for $\mathrm{HoCo}_{2}$ calculated (i) from DSC measurements sweeping the temperature (open circles) and sweeping the field (open squares), (ii) from $M(T)$ and $M(H)$ using the Clausius-Clapeyron equation (full circles and full squares, respectively), and (iii) from $M(H)$ using the Maxwell relation being $5 \mathrm{~T}$ the maximum applied magnetic field (full diamonds; continuous line is drawn as a guide to the eye).

to $50 \%$ larger for the higher temperatures and fields.

For $\mathrm{ErCo}_{2}, \Delta S$ values have been obtained from calorimetric and magnetization data as described in Ref. 64. Values are shown in Fig. 13 as a function of the temperature. As for the $\mathrm{HoCo}_{2}$ compound, the agreement in $\mathrm{ErCo}_{2}$ among $\Delta S$ values obtained from isofield measurements on one hand and among the isothermal results on the other is remarkable. Furthermore, isofield values are also up to $25 \%$ higher than the isothermal ones.

This data analysis is not applicable to the $\mathrm{DyCo}_{2}$ sample due to the extreme broadness of the transition. First, in the calorimetric curves at constant temperature, it is not possible to estimate a baseline for the lower fields and hence the integration of the signal is not reliable. Second, and as stated in Sec. II, the shape of $M(H)$ curves do not allow to estimate

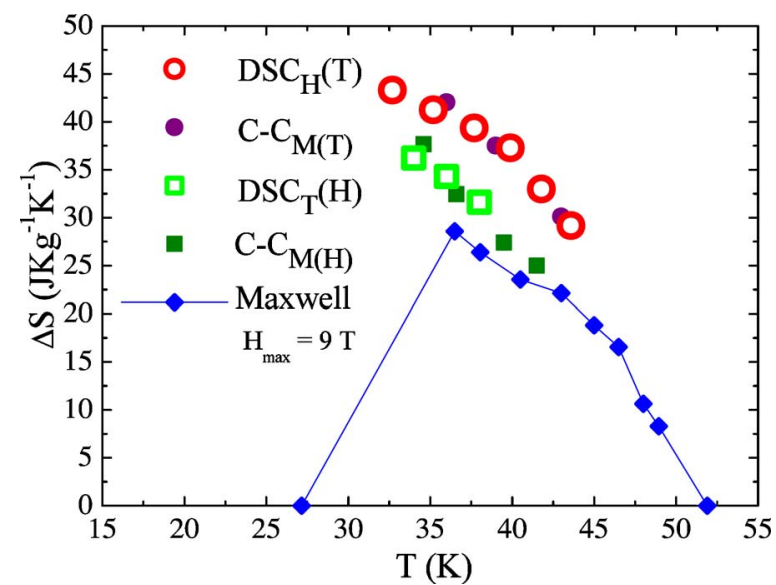

FIG. 13. (Color online) Entropy change for $\mathrm{ErCo}_{2}$ calculated (i) from DSC measurements sweeping the temperature (open circles) and sweeping the field (open squares), (ii) from $M(T)$ and $M(H)$ using the Clausius-Clapeyron equation (full circles and full squares, respectively), and (iii) from $M(H)$ using the Maxwell relation being $9 \mathrm{~T}$ the maximum applied magnetic field (full diamonds, continuous line is drawn as a guide to the eye). 
the magnetization jump and thus $\Delta S$ at transition. Consequently, we could not obtain isothermal $\Delta S$ values in $\mathrm{DyCo}_{2}$ to compare them with the corresponding isofield values.

At least three phenomena may lead to the mentioned difference in $\Delta S$ obtained from isofield and isothermal measurements, all of them being a consequence of the nonideality of the first-order transition. In the isothermal process, the applied magnetic field is increased throughout the transition region and, hence, magnetic work is done to the system. This fact produces an additional negative contribution to the entropy change which can be estimated as

$$
w=\frac{1}{T} \int_{H_{a}}^{H_{b}} M d H,
$$

where the integral extends only over the transition region. ${ }^{63}$ In the case of $\mathrm{HoCO}_{2}$, this term accounts for $20-30 \%$ of the difference between the values of $\Delta S$ obtained from isofield and isothermal processes, while for $\mathrm{ErCo}_{2}$, this term is strongly dependent on the temperature. In a range of $5 \mathrm{~K}$, the term $(1 / T) \int M d H$ varies from $10 \%$ to $100 \%$ of the difference between $\Delta S$ obtained from isofield and isothermal measurements. Moreover, the broadness of the transition also implies that the initial and final states involved in the two different kinds of experiments are not equivalent. Hence we want to stress that care should be taken when comparing $\Delta S$ values obtained from experiments in which the driving physical parameters are different.

Finally, the presence of hysteresis, as evidenced in Figs. 5 and 6, reveals that the samples did not reach full thermodynamical equilibrium during the experiments, in which the transitions spanned over a time window of the order of $10^{2}-10^{3} \mathrm{~s}$. The Maxwell relations and the ClausiusClapeyron equation are valid only in equilibrium, but the agreement between $\Delta S$ obtained from the analysis of magnetization data and those obtained directly from DSC indicates that this is not at the origin of the differences observed (see Figs. 12 and 13). Conversely, the lack of thermodynamical equilibrium may lead to dissipation and might account, at least partially, for the differences in $\Delta S$ between field and temperature driven transitions.

\section{CONCLUSIONS}

To conclude, we review the most relevant results obtained in this work:

(i) In contrast with recent experiments, ${ }^{23}$ the results from our DSC measurements under applied field in $\mathrm{PrCO}_{2}$ and $\mathrm{NdCo}_{2}$ reveal unambiguously the second-order nature of their ferromagnetic transitions.

(ii) The calorimetric curves for $\mathrm{ErCO}_{2}$ and $\mathrm{HoCO}_{2}$ ob- tained by sweeping the temperature at different fields and sweeping the field at different temperatures show the expected features for a first-order transition: sharp peaks, temperature and field hysteresis, and dependence of the critical temperature with the applied field. $\mathrm{DyCo}_{2}$ shows the typical dependence of the critical temperature with the applied field for a first-order transition. However the corresponding calorimetric curves show rather broad peaks and no thermal or field hysteresis, evidencing the weak first-order character of the transition.

(iii) Three main peaks are observed in $\mathrm{ErCo}_{2}$ calorimetric curves as well as in the derivative of $M(H)$, which we relate with the anisotropy of the coexistence curve $H_{c}-T_{c}$ found in the $\mathrm{ErCo}_{2}$ single crystal. ${ }^{50}$

(iv) The latent heats, entropy changes, and critical temperatures obtained from our DSC measurements suggest that the latent heats in $\mathrm{RCo}_{2}$ are governed by the structural changes at the transition.

(v) We have determined $\Delta S$ from DSC and magnetization data in $\mathrm{ErCo}_{2}$ and $\mathrm{HoCo}_{2}$. This analysis demonstrates that isofield and isothermal processes yield different $\Delta S$ values at the magnetostructural transition. The work that the magnetic field does over the system ${ }^{63}$ in the isothermal process accounts for a fraction of the difference. However, the broadness of their transitions also implies that the initial and final states involved in the two kinds of processes are not the same and therefore $\Delta S$ at the isothermal and isofield transitions may be different, depending on the particular shape of the $M(H, T)$ surface. This fact not only explains discrepancies that appear in the literature concerning the $\mathrm{RCo}_{2}$ series ${ }^{15-20}$ but also other systems, as the giant magnetocaloric $\mathrm{Gd}_{5}\left(\mathrm{Si}_{x} \mathrm{Ge}_{1-x}\right)_{4}$ alloys. ${ }^{63}$ The magnitude of the discrepancies (up to $50 \%$ in some cases) imply that in order to appropriately evaluate $\Delta S$ in materials of potential use in cooling devices, the path followed to induce first-order magnetostructural transitions should be carefully taken into account.

\section{ACKNOWLEDGMENTS}

This work has been partially funded by the Fundación Areces, the Spanish CICYT research Projects Nos. MAT2002-04178-C04-03, MAT2005-002454, and MAT2003-01124, the FEDER program, the Aragonese CAMRADS research group, and the Catalan DURSI research Project No. 2001SGR00066. We thank N. Plugaru and M. J. Pastor for sample preparation, Ll. Mañosa, A. Planes, and L. Morellón for fruitful discussions, J. Rodríguez and J. Sánchez-Marcos for their magnetization facilities at the Universidad de Cantabria, and J. Bartolomé for a critical reading of the manuscript. J.H. acknowledges MEC for the Ph.D. grant.

\footnotetext{
*Electronic address: Julia.Herrero@unizar.es

${ }^{1}$ N. H. Duc and P. E. Brommer, in Handbook of Magnetic Materials, edited by K. H. J. Buschow (Elsevier Science, New York, 1999), Vol. 12.
}

${ }^{2}$ E. Gratz and A. S. Markosyan, J. Phys.: Condens. Matter 13, R385 (2001).

${ }^{3}$ T. Goto, K. Fukamichi, T. Sakakibara, and H. Komatsu, Solid State Commun. 72, 945 (1989). 
${ }^{4}$ R. Moon, W. C. Koehler, and J. Farrell, J. Appl. Phys. 36, 978 (1965).

${ }^{5}$ P. Hendy and E. W. Lee, Phys. Status Solidi A 50, 101 (1978).

${ }^{6}$ J. W. Ross and J. Crangle, Phys. Rev. 133, A509 (1964).

${ }^{7}$ L. Morellon, P. A. Algarabel, M. R. Ibarra, J. Blasco, B. GarciaLanda, Z. Arnold, and F. Albertini, Phys. Rev. B 58, R14721 (1998).

${ }^{8}$ C. Magen, L. Morellon, P. A. Algarabel, M. R. Ibarra, Z. Arnold, J. Kamarad, T. A. Lograsso, D. L. Schlagel, V. K. Pecharsky, A. O. Tsokol, and K. A. Gschneider, Jr., Phys. Rev. B 72, 024416 (2005).

${ }^{9}$ H. Wada and Y. Tanabe, Appl. Phys. Lett. 79, 3302 (2001).

${ }^{10}$ O. Tegus, E. Brück, K. H. J. Buschow, and F. R. de Boer, Nature (London) 415, 150 (2002).

${ }^{11}$ K. A. Gschneider and V. K. Pecharsky, Annu. Rev. Mater. Sci. 30, 378 (2000).

${ }^{12}$ A. M. Tishin, in Handbook of Magnetic Materials, edited by K. H. J. Buschow (Elsevier Science, New York, 1999), Vol. 12.

${ }^{13}$ A. M. Tishin and Y. I. Spichkin, The Magnetocaloric Effect and its Applications, 1st ed. (Institute of Physics, New York, 2003).

${ }^{14}$ K. A. Gschneidner, V. K. Pecharsky, and A. O. Tsokol, Rep. Prog. Phys. 68, 1479 (2005).

${ }^{15}$ A. Giguere, M. Foldeaki, W. Schnelle, and E. Gmelin, J. Phys.: Condens. Matter 11, 6969 (1999).

${ }^{16}$ H. Wada, S. Tomekawa, and M. Shiga, Cryogenics 39, 915 (1999).

${ }^{17}$ H. Wada, S. Tomekawa, and M. Shiga, J. Magn. Magn. Mater. 196-197, 689 (1999).

${ }^{18}$ N. A. de Oliveira, P. J. vonRanke, M. V. Tovar Costa, and A. Troper, Phys. Rev. B 66, 094402 (2002).

${ }^{19}$ N. H. Duc and D. T. K. Anh, J. Magn. Magn. Mater. 242-245, 873 (2002).

${ }^{20}$ N. H. Duc, D. T. K. Anh, and P. E. Brommer, Physica B 319, 1 (2002)

${ }^{21}$ F. Givord and J. S. Shah, Comptes Reñdues Acad. Sci. Paris B 247, 923 (1972).

${ }^{22}$ F. Pourarian, Ph.D. thesis, Southampton University (1974).

${ }^{23}$ M. Forker, S. Müller, P. de la Presa, and A. F. Pasquevich, Phys. Rev. B 68, 014409 (2003).

${ }^{24}$ D. Bloch, D. Edwards, M. Shimizu, and J. Voiron, J. Phys. F: Met. Phys. 5, 1217 (1975).

${ }^{25}$ J. Inoue and M. Shimizu, J. Phys. F: Met. Phys. 12, 1811 (1982).

${ }^{26}$ J. Inoue and M. Shimizu, J. Phys. F: Met. Phys. 18, 2487 (1988).

${ }^{27}$ S. Khmelevskyi and P. Mohn, J. Phys.: Condens. Matter 12, 9453 (2000).

${ }^{28}$ J. Marcos, F. Casanova, X. Batlle, A. Labarta, A. Planes, and L. Mañosa, Rev. Sci. Instrum. 74, 4768 (2003).

${ }^{29}$ F. Casanova, X. Batlle, A. Labarta, J. Marcos, L. Mañosa, and A. Planes, Phys. Rev. B 66, 212402 (2002).

${ }^{30}$ F. Casanova, A. Labarta, X. Batlle, F. J. Pérez-Reche, E. Vives, L. Mañosa, and A. Planes, Appl. Phys. Lett. 86, 262504 (2005).

${ }^{31}$ R. Moon, W. C. Koehler, H. R. Child, and L. J. Raubenheimer, Phys. Rev. 176, 722 (1968).

${ }^{32}$ H. Imai, H. Wada, and M. Shiga, J. Magn. Magn. Mater. 140144, 835 (1995).

${ }^{33}$ R. Hauser, E. Bauer, and E. Gratz, Phys. Rev. B 57, 2904 (1998).

${ }^{34}$ O. Syshenko, T. Fujita, V. Sechovsky, M. Divis, and H. Fujii, J. Alloys Compd. 317-318, 438 (2001).
${ }^{35}$ O. Syshchenko, T. Fujita, V. Sechovsky, M. Divis, and H. Fujii, Phys. Rev. B 63, 054433 (2001).

${ }^{36}$ T. Nakama, M. Hedo, A. Sawada, Y. Shimoji, M. Tokumura, K. Uchima, K. Yagasaki, H. Niki, and A. T. Burkov, Physica B 312-313, 867 (2002).

${ }^{37}$ N. H. Duc, T. D. Hien, P. E. Brommer, and J. J. M. Franse, Physica B \& C 149, 352 (1988).

${ }^{38}$ D. Bloch, F. Chaisee, F. Givord, J. Voiron, and E. Burzo, J. Phys. (Paris) 32, C1 (1971).

${ }^{39}$ E. Burzo, Int. J. Magn. 3, 161 (1972).

${ }^{40}$ J. Farrel and W. E. Wallance, Inorg. Chem. 5, 105 (1966).

${ }^{41}$ E. W. Lee and F. Pourarian, Phys. Status Solidi A 33, 483 (1976).

${ }^{42}$ A. S. Markosyan, Fiz. Tverd. Tela (Leningrad) 23, 1956 (1981).

${ }^{43}$ N. H. Duc, T. D. Hien, P. E. Brommer, and J. J. M. Franse, J. Phys. F: Met. Phys. 18, 275 (1988).

${ }^{44}$ J. Voiron, A. Berton, and J. Chaussy, Phys. Lett. 50A, 17 (1974).

${ }^{45}$ N. H. Duc, T. D. Hien, P. P. Mai, N. H. K. Ngan, N. H. Sinh, P. E. Brommer, and J. J. M. Franse, Physica B 160, 199 (1989).

${ }^{46}$ H. K. M. Rosen, J. Magn. Magn. Mater. 7, 361 (1978).

${ }^{47}$ J. Herrero-Albillos, F. Casanova, F. Bartolomé, L. M. García, A. Labarta, and X. Batlle, J. Magn. Magn. Mater. 290-291, 682 (2005).

${ }^{48}$ E. Gratz, R. Hauser, A. Lindbaum, M. Maikis, R. Resel, G. Schaudy, R. Z. Levitin, A. S. Markosyan, I. S. D. A. Y. Sokolov, and S. W. Zochowski, J. Phys.: Condens. Matter 7, 597 (1995).

${ }^{49}$ D. H. Wang, S. L. Tang, H. D. Liu, W. L. Gao, and Y. W. Du, Intermetallics 10, 819 (2002).

${ }^{50}$ V. V. Aleksandryan, N. V. Baranov, A. I. Kozlov, and A. S. Markosyan, Fiz. Met. Metalloved. 66, 682 (1988).

${ }^{51}$ N. V. Baranov and A. I. Kozlov, J. Alloys Compd. 190, 83 (1992).

${ }^{52}$ E. Gratz, A. S. Markosyan, I. Y. Gaidukova, V. E. Rodimin, S. Berger, E. Bauer, and H. Michor, Solid State Commun. 120, 191 (2001).

${ }^{53}$ S. A. Nikitin and A. M. Tishin, Cryogenics 31, 166 (1991).

${ }^{54}$ M. Foldeaki, A. Giguère, R. Chahine, and T. K. Bose, Adv. Cryog. Eng. 43, 1533 (1997).

${ }^{55}$ H. Wada, T. Morikawa, Taniguchi, T. Shibata, Y. Yamada, and Y. Akishige, Physica B 328, 114 (2003).

${ }^{56}$ F. Casanova, X. Batlle, A. Labarta, J. Marcos, L. Mañosa, and A. Planes, J. Appl. Phys. 93, 8313 (2003).

${ }^{57}$ A. Giguère, M. Foldeaki, B. Ravi Gopal, R. Chahine, T. K. Bose, A. Frydman, and J. A. Barclay, Phys. Rev. Lett. 83, 2262 (1999).

${ }^{58}$ P. von Ranke, N. de Oliveira, and S. Gamae, Phys. Lett. A 320, 302 (2004).

${ }^{59}$ D. Gignoux, F. Givord, R. P. de la Bathie, and F. Sayetat, J. Phys. F: Met. Phys. 9, 763 (1979).

${ }^{60}$ V. Goldberg-Murmis, Y. Atzmony, and M. P. Dariel, J. Mater. Sci. 15, 127 (1980).

${ }^{61}$ F. Casanova, X. Batlle, A. Labarta, J. Marcos, L. Mañosa, and A. Planes, Phys. Rev. B 66, 100401(R) (2002).

${ }^{62}$ F. Casanova, A. Labarta, X. Batlle, J. Marcos, L. Mañosa, A. Planes, and S. de Brion, Phys. Rev. B 69, 104416 (2004).

${ }^{63}$ F. Casanova, A. Labarta, X. Batlle, E. Vives, J. Marcos, L. Mañosa, and A. Planes, Eur. Phys. J. B 40, 427 (2004).

${ }^{64}$ J. Herrero-Albillos, F. Bartolomé, L. M. García, F. Casanova, A. Labarta, and X. Batlle, J. Magn. Magn. Mater. 301, 378 (2006). 